\title{
Improved plastid transformation efficiency in Scoparia dulcis $\mathbf{L}$.
}

\author{
Srinivas Kota $\cdot$ Qiang Hao $\cdot$ Muralikrishna Narra $\cdot$ Vaishnavi Anumula $\cdot$ A.V Rao $\cdot$ Zanmin Hu $\cdot$ Sadanandam Abbagani
}

Received: 1 July 2019 / Revised: 26 September 2019 / Accepted: 26 September 2019

(c) Korean Society for Plant Biotechnology

\begin{abstract}
The high expression level of industrial and metabolically important proteins in plants can be achieved by plastid transformation. The CaIA vector, a Capsicumspecific vector harboring aadA (spectinomycin resistance), is a selectable marker controlled by the $P s b A$ promoter, and the terminator is flanked by the trnA and $\operatorname{trnI}$ regions of the inverted repeat (IR) region of the plastid. The CaIA vector can introduce foreign genes into the IR region of the plastid genome. The biolistic method was used for chloroplast transformation in Scoparia dulcis with leaf explants followed by antibiotic selection on regeneration medium. Transplastomes were successfully screened, and the transformation efficiency of 3 transgenic lines from 25 bombarded leaf explants was determined. Transplastomic lines were evaluated by PCR and Southern blotting for the confirmation of aadA insertion and its integration into the chloroplast genome. Seeds collected from transplastomes were analyzed on spectinomycin medium with wild types to determine genetic stability. The increased chloroplast transformation efficiency (3 transplastomic lines from 25 bombarded explants) would be useful for expressing therapeutically and industrially important genes in Scoparia dulcis L.
\end{abstract}

Keywords Scoparia dulcis L., Heterologous vectors, CaIA plastid vector, Inverted repeat region, Transplastomic lines

\section{Introduction}

Past two and half decades, in higher plants, plastome engineering technology research advanced in various ways by expressing different transgenes in plastids. The integration and the expression of transgenes in the plastome offer

S. Kota $\cdot$ Q. Hao $\cdot$ M. Narra $\cdot$ V. Anumula $\cdot$ A.V Rao $\cdot$ Z. Hu S. Abbagani $(\square)$

Department of Biotechnology, Kakatiya University, Warangal, India- 506009

e-mail: nandamas@gmail.com several advantages over the nuclear transformation in plants. These include biological containment of transgene pollen transmission, high level gene expression, feasibility to express polycistronic mRNA with a single promoter, lack of gene silencing and position effect, specific target insertion with homologous recombination (Heifetz 2000; Maliga 2004; Ruf et al. 2001). First successful plastid transformation was reported in Chlamydomonas reindhartii (Boynton et al. 1988). Later, it has been expanded to various higher plants i.etobacco (Svab et al. 1990), potato (Sidorov et al. 1999a), Brassica (Cheng et al. 2010), Arabidopsis (Sikdar et al. 1998), tomato (Ruf et al. 2001), Soybean (Dufourmantel et al. 2004), lettuce (Kanamoto et al. 2006), Oryza sativa (Lee et al. 2006; Wang et al. 2018), cotton (Kumar et al. 2004b), brinjal (Singh et al. 2010), Scoparia (Muralikrishna et al. 2016; Narra et al. 2018a), Maize (Sidorov et al. 2019) and Capsicum (Kota et al. 2019),etc. Flanking regions of insertional sequences and selectable markers are the crucial elements to develop species-specific chloroplast transformation vector (Wang et al. 2009). Species specific vectors are useful to increase plastid transformation efficiency but specific vectors are always not needed to achieve transplastomes in heterologous systems. Genes related to agronomic traits such as biotic stress and abiotic stress have also been expressed in crop plants (Dufourmantel et al. 2004; Hou et al. 2003; Kumar et al. 2004a). Chloroplast vector is designed by identifying transcriptionally inactive regions and regulatory sequences that accelerate the expression of the transgene (Madanala et al. 2012)

Scoparia dulcis L. is an erect herb belongs to the family Plantaginaceae. The genus Scoparia have been used in crude methods associated with the study of traditional medicine. In view of its wide acceptance in ethnomedicine, it has attracted enormous attention from the scientific community for its medicinal value and thus remained a subject of intensified research. The chemical compounds isolated from this plant contain antiulcer (Girish et al. 
2011), antidiabetic (Saikia et al. 2011), antihyperlipidemic (Pari and Latha 2006), anti-inflammatory (De Farias Freire et al. 1993) and some other compounds were screened which has medicinal properties.

In our lab, a reliable regeneration, Agrobacterium and biolistic mediated genetic transformation using uidA, hpt and gus and $n p t I I$ genes respectively in $S$. dulcis (Aileni et al. 2011a; Srinivas et al. 2016). In Scoparia dulcis, efficient plant regeneration system comparable to model plant system like tobacco using leaf explant made more convenient to achieve reliable chloroplast transformation by targeting $r p l 32 / t r n L$ and $\operatorname{trnR} / \operatorname{trnN}$ insertional sites of SSC and IR regions of plastid genome using pFaadAII and $\mathrm{KNTc}$ heterologous vectors respectively (Muralikrishna et al. 2016; Narra et al. 2018a). The present study is focused to improve plastid transformation efficiency by targeting a new insertion site of plastid genome IR region of $S$. dulcis. The improved transformation efficiency will be further useful to enhance diterphinoids like scopadulcic acid B (SDB) and scoparic acid A (SA) by transforming their respective genes, industrially and economically important genes in the chloroplast genome to improve biopharmaceutical products.

\section{Materials and Methods}

\section{Establishment of axenic cultures}

For culture maintenance, nodal segments of S.dulcis were inoculated on semi-solid MS (Murashige and Skoog) (Murashige and Skoog 1962) medium supplemented with $2 \%$ sucrose and $0.8 \%$ of agar-agar were used, culture conditions were maintained $25 \pm 2^{\circ} \mathrm{C}$ under $16 / 8$ hrs photoperiod with cool white fluorescent lamps (Philips) of 30 $\mu \mathrm{mol} \mathrm{m} \mathrm{m}^{-2} \mathrm{~s}^{-1}$ light intensity. Young leaves were used as explants for the transformation experiment to get transgenic plants by stabilized regeneration protocol i.e $4 \mathrm{mg} / \mathrm{L} \mathrm{6-BAP}$ and $0.2 \mathrm{mg} / \mathrm{L}$ IAA (Aileni et al. 2011b).

Chloroplast vector used for the transformation

The chloroplast transformation vector CaIA (Fig. 1) (Kota et al. 2019) containing $\operatorname{trn} A$ and $\operatorname{trnI}$ of chloroplast IR regions from Capsicum annum L. carrying aadA which was controlled by $p s b A$ promoter and terminator used as a selectable marker to screen transplastomic lines under optimized selection pressure ( $75 \mathrm{mg} / \mathrm{L}$ spectinomycin).

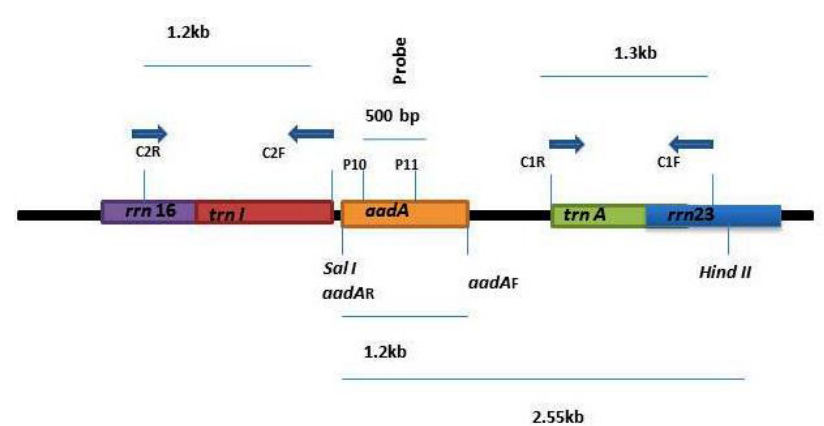

Fig. 1 Physical map of the CaIA vector with all primers and the probe

Biolistic transformation of chloroplast vector (CaIA) in Scoparia dulcis L.

In vitro grown leaves of Scoparia dulcis L. were used as the explants for the plastid transformation using CaIA vector. Genetix plasmid DNA isolation kit was used to extract plasmid DNA from E.coli cells (Genentix Biotech Asia Pvt Lt, New Delhi, India). CaIA vector DNA was coated on $0.6 \mu$ size gold particle by adding $\mathrm{CaCl}_{2}(2.5 \mathrm{M}$, filter-sterilized), Spermidine (0.1M, free-base, filter-sterilized, aliquoted and frozen at $-20^{\circ} \mathrm{C}$ ), Sterile $\mathrm{dH}_{2} \mathrm{O}$ ) (Srinivas et al. 2016; Verma et al. 2008). The complete experiment was performed by using biolistic apparatus (Biolistic PDS1000/He Particle Delivery System, Bio-Rad, Hercules, CA).

Leaf explants of one month old culture were excised and placed at the middle of Petri plate containing regeneration medium. Leaf tissue was bombarded at standardized biolistic parameters i.e $6 \mathrm{~cm}$ flight distance and 650 psi pressure were employed for the transformation (Srinivas et al. 2016). Each plate containing 5 explants, totally twenty-five explants were bombarded and cultured for two days on the same medium at $25 \pm 2^{\circ} \mathrm{C}$, photoperiod is $16 / 8 \mathrm{hrs}$. Later tissues were cut into desired size $1 \mathrm{~cm}^{2}$ and placed on selection medium (MS medium, $4 \mathrm{mg} / \mathrm{L}$ BAP and $0.2 \mathrm{mg} / \mathrm{L} \mathrm{IAA}$ and $75 \mathrm{mg} / \mathrm{L}$ spectinomycin) (Muralikrishna et al. 2016), selection pressure was maintained throughout the screening process. Tissue was subcultured every two weeks. Resistant shoot buds were observed after three weeks, these shoots buds were maintained on the same media for shoot bud proliferation up to three weeks. Proliferated shoots were excised shifted on to the MS basal medium on same selection pressure. For rooting, after six weeks, individual shoots were maintained on half strength MS along with 1 $\mathrm{mg} / \mathrm{L}$ Indole-3-butyric acid. 
Molecular screening of Scoparia dulcis L. transplastomic lines

\section{PCR detection}

Total DNA from the putative transplastomic lines was isolated (Doyle 1991) and used for PCR confirmation. PCR experiments were done to confirm different integrations by using three different sets of primers. Primers ARCGCGATCGATAAGCTTCCGATC, AR- CGCGGTCGA CCATGAATAAATG were used to screen aadA gene presence in the transformed plants. PCR conditions were followed for 30 cycles- $95^{\circ} \mathrm{C}$ for $3 \mathrm{~min}, 94^{\circ} \mathrm{C}$ for 40 $\mathrm{Sec}, 55^{\circ} \mathrm{C}$ for $40 \mathrm{Sec}, 72^{\circ} \mathrm{C}$ for $2 \mathrm{~min}$.

The other PCR was performed to confirm aadA integration in the plastome. Primers $\mathrm{Cl}$ F GCGC CCC GGG TGC ATG CTC CAC and C2 R CGCG GTC GAC AGC ATG CATG AA gives $3.7 \mathrm{~kb}, 2.5 \mathrm{~kb}$ in homoplasmic lines and wild type respectively. PCR conditions were set up as 30 cycles- $95^{\circ} \mathrm{C}$ for $3 \mathrm{~min}, 94^{\circ} \mathrm{C}$ for $40 \mathrm{Sec}, 58^{\circ} \mathrm{C}$ for $40 \mathrm{Sec}$, $72^{\circ} \mathrm{C}$ for $3 \mathrm{~min}$ and $20 \mathrm{Sec}$.

\section{Confirmation of transplastomic lines by Southern blotting}

Chloroplast integration of aadA was confirmed by southern blotting of total genomic DNA from transplastomic and wild type plants. Isolated $3 \mu \mathrm{g}$ genomic DNA was digested Sal I and Hind III restriction enzymes and subject to electrophoresis on $0.8 \%$ agarose gel. Digested DNA fragments were transferred on to Nylon $\mathrm{H}^{+}$membrane (Roche, USA). Non-radioactive probes (DIG labeled, Roche, USA) was used to identify the presence of aadA integration into the chloroplast genome. P10 and P11 primers were used to amplify $500 \mathrm{bp}$ of aadA segment. This amplified product was labeled with DIG labeling kit (Roche, USA) and used as a probe for detection of southern blotting (Fig. 3).

Genetic stability of transplastomic lines

aadA stability was analyzed in transplastomic lines seed progeny on MS basal medium employing with same selection pressure. Self-pollinated transplastomic seeds were raised and examined along with wild seeds.

\section{Results}

Chloroplast transformation of Scoparia dulcis L.

In the current experiment, employing optimized biolistic

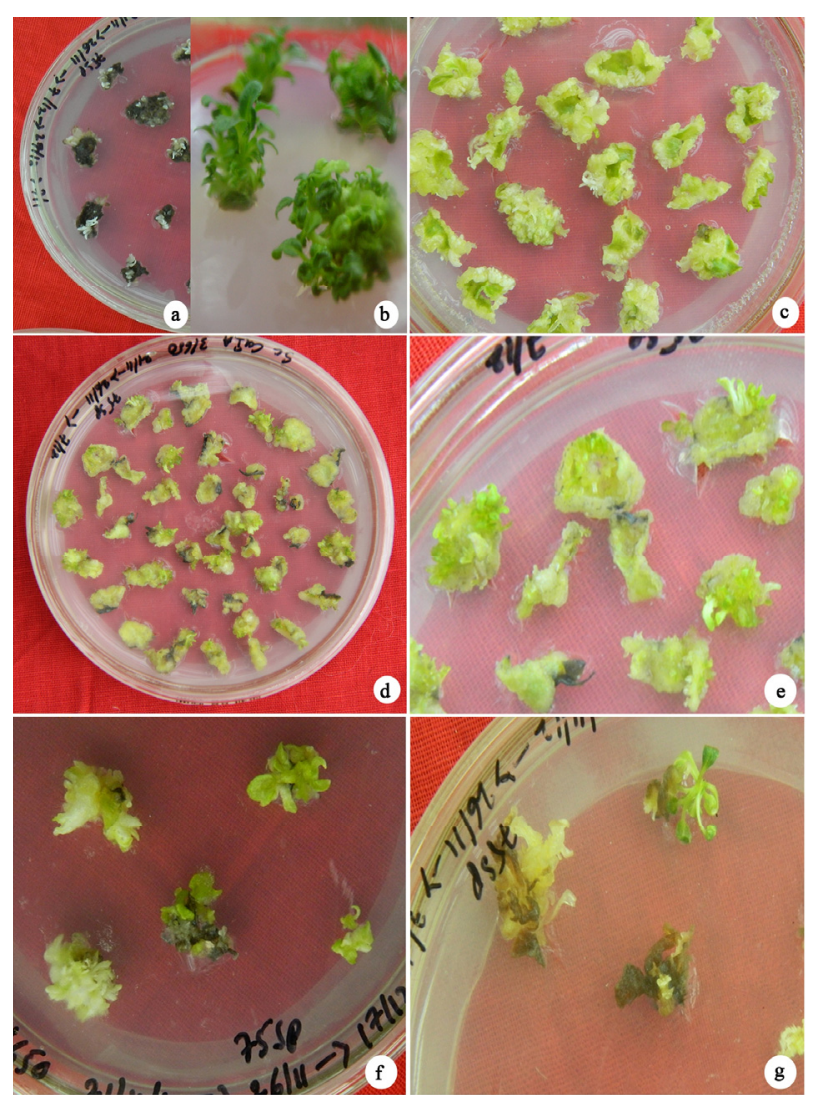

Fig. 2 Recovery of the transplastomic lines of Scoparia dulcis L

a) Control explants on selection medium ( $75 \mathrm{mg} / \mathrm{L}$ spectinomycin).

b) Control explants on regeneration medium without selection pressure.

c) Bombarded explants showing differentiation initiation on selection medium after two weeks.

d) Initiation of putative transplastomic shoot buds on selection medium.

e \& f) Proliferation of transplastomic shoot buds on selection medium.

g) Proliferated shoot buds on MS basal medium with selection pressure.

parameters, gold-coated chloroplast transformation vector CaIA which targets trnA and trnI regions of IR region was bombarded in 5 plates (each plate contains 5 leaf explants) of Scoparia dulcis L. with leaf explants. Three days after bombardment, the explants were shifted on to the selection medium containing $75 \mathrm{mg} / \mathrm{L}$ spectinomycin for primary screening along with control (Fig. 2a). These tissues were subcultured at a regular interval of 10 days on to the same selection medium. Two weeks after the bombardment, initiation of differentiation (Fig. 2c) was observed. Three weeks after the bombardment initiation of shoot buds observed (Fig. 2d) in Scoparia dulcis L. and it is further sub-cultured for the proliferation of shoot buds (Fig. 2e \& f) and it was achieved after five weeks. Proliferated shoot buds were subcultured on MS basal medium with antibiotic 

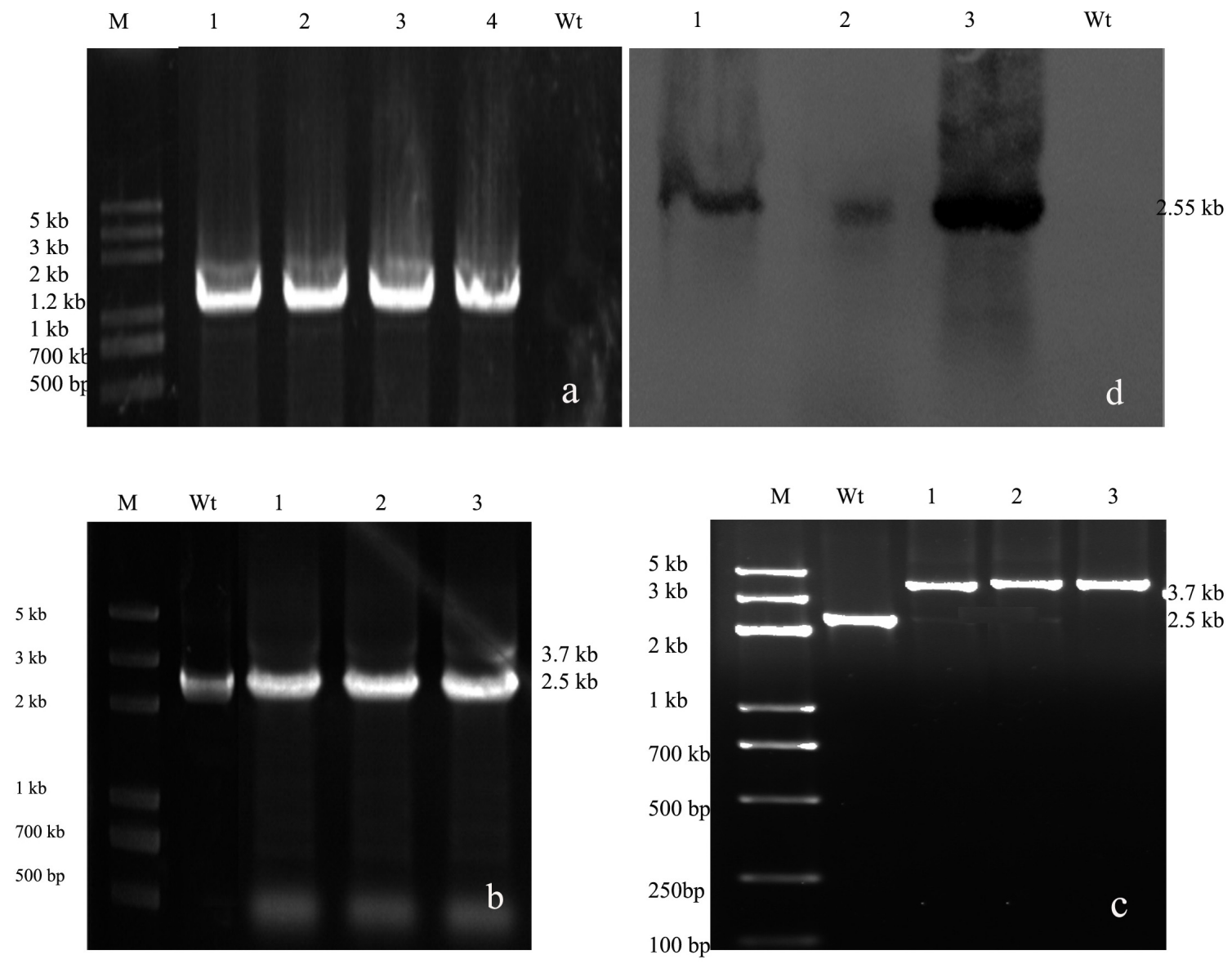

Fig. 3 Molecular confirmation of the transplastomic lines of Scoparia dulcis L.

a) Confirmation of aadA in transplastomic lines showing a $1.2 \mathrm{~kb}$ amplicon; $\mathrm{M}$ - marker, Wt - wild type, 1, 2, 3, \& 4 - transplastomic lines.

b) Confirmation of the heteroplasmic state showing 2.5 and $3.7 \mathrm{~kb}$ amplicons; $\mathrm{M}$ - marker, $\mathrm{Wt}$ - wild type, 1, 2, \& 3 - transplastomic lines.

c) Homoplasmic state confirmation by stable integration of aadA into the plastome of $S$. dulcis showing 3.7 and $2.5 \mathrm{~kb}$ amplicons with PCR in transplastomes and wild type plants, respectively.

d) Southern blotting confirmation of aadA in plastomes showing a $2.55 \mathrm{~kb}$ amplicon and absence of the same band in the wild type using the $\operatorname{aadA}$ probe.

for shoot elongation (Fig. 2g). At this point, putative DNA was isolated from transplastomic lines were subjected to PCR for molecular screening. Most of the putative plants found as heteroplasmic lines, after few repetitive subculture heteroplasmic lines were sorted out to homoplasmic lines. Homoplasmic lines were shifted to rooting and greenhouse. The complete experiment was repeated thrice.

Molecular screening of transplastomic Scoparia dulcis L.

The total genome was isolated from the putative transgenic plants for molecular identification. Initially, aadA was screened by PCR using specific primers, $1.2 \mathrm{~kb}$ aadA DNA band was observed whereas no band was observed in wild (Fig. 3a).

aadA integration was confirmed with specific primers
(C1F and $\mathrm{C} 2 \mathrm{R}$ ) which amplifies left, right flanks along with aadA. Tested putative transgenics were found as heteroplasmic state which gave 2.5 and $3.7 \mathrm{~kb}$ amplicons in PCR reaction (Fig. 3b), $2.5 \mathrm{~kb}$ represents the presence of only flanking regions and $3.7 \mathrm{~kb}$ represents $1.2 \mathrm{~kb}$ size aadA integration into flanks. After repetitive subculture of putative transplastomic lines, PCR confirmation found to be the homoplasmic state by producing $3.7 \mathrm{~kb}$ in transplastomic lines whereas only $2.5 \mathrm{~kb}$ amplicon was observed in wild (Fig. 3c). Out of three independent experiments, in each experiment three lines found to be PCR positive and the same lines were tested for southern blot confirmed integration (Table 1), previous reports have shown that two transplastomic lines from 25 bombarded explants. 
Table 1 Transplastomic lines of $S$. dulcis obtained in three independent experiments using the CaIA vector

\begin{tabular}{ccccc}
\hline Sl. No & $\begin{array}{c}\text { No. of bombarded } \\
\text { explants }\end{array}$ & $\begin{array}{c}\text { Shoot buds with } \\
\text { spectinomycin resistance }\end{array}$ & PCR positives & $\begin{array}{c}\text { Southern blot } \\
\text { positives }\end{array}$ \\
\hline 1 & 25 & 5 & 3 & 3 \\
2 & 25 & 5 & 3 & 3 \\
3 & 25 & 4 & 3 & 3 \\
\hline
\end{tabular}

Confirmation of transplastomic lines by southern blot analysis

Amplified 500 bp length of aadA fragment by using P10 and P11 primers was used as a probe by labelling with DIG kit (Roche applied sciences, Germany). $2.55 \mathrm{~kb}$ band was observed in transplastomic lines $(1.2 \mathrm{~kb}$ aad $A+1.3 \mathrm{~kb}$ left flank and $50 \mathrm{bp}$ from the plastome region), it confirms the integration of aadA into plastid region (Fig. 3d). Whereas, no band was observed in wild type plant because the used probe (500 bp of aadA) shows only integration of aadA with left side flank.

Seed germination confirmation

The seed germination experiment of self-pollinated transplastomic lines was examined by growing the seedlings on MS basal medium containing $75 \mathrm{mg} / \mathrm{L}$ spectinomycin antibiotic. Stability of transplastomic nature confirmed by germination of green seedlings on antibiotic medium confirms the stable integration of aadA (Fig. 4a). Whereas, germinated wild type seeds were bleached completely on antibiotic medium and failed to produce green seedlings (Fig. 4b).

\section{Discussion}

Plastid transformation in crop plants like tobacco, potato, rice, cabbage, tomato, eggplant, rapeseed and other economically important plants like cotton and bitter melon are well established. Extending Plastome engineering of the medicinally important plant, Scoparia dulcis L., opens greater advancement of expressing high level gene expression of various therapeutic and industrially important components through transplastomic technology.

In $S$. dulcis there are some previous reports which show the presence of some secondary metabolites having medicinal properties (Hayashi 1999) like 6-methoxybenzoxazolinone (hypotensive activity) (Chiu-Ming and Ming-Tyan 1976), scopadulcic acid B having anti tumor \& inflammatory (Hayashi et al. 1992a; Miyahara et al. 1996), inhibitory



Fig. 4 Confirmation of the stability of transplastomes by seed progeny analysis on antibiotics

a) Transplastomic seed analysis confirmed the stability of progeny by germinating green seedlings on antibiotic medium $(75 \mathrm{mg} / \mathrm{L})$.

b) Wild type seeds failed to grow in green on antibiotic medium and were bleached completely.

effect of replication of HSV-1 (Hayashi et al. 1988)and scoparic acid $\mathrm{A}$ is a strong inhibitor of $\beta$-glucuronidase (Hayashi et al. 1992b).

The successful genetic transformation was reported in S.dulcis (Aileni et al. 2011a; Yamazaki et al. 1996), plastid transformation is also successfully established in this plant. Here, we are reporting an increased plastid transformation efficiency protocol in Scoparia dulcis L. using leaf explants. High regeneration efficiency of leaf explant made easy to use the leaf as explant for the plastid transformation experiment. In fact leaf is suitable explant for the expression 
of foreign genes in to the chloroplast, similar kind leaf used as experimental tissue for the chloroplast transformation in plants potato (Sidorov et al. 1999b), cotton (Kumar et al. 2004a), tobacco (Svab and Maliga 1993) and tomato (Ruf et al. 2001).

In the current experiment, we successfully screened the transplastomic lines of $S$. dulcis using an efficient selection process on spectinomycin antibiotic. Stable integration of chloroplast transformation was achieved in tobacco, lettuce, Cedrelaodorata, Capsicum and Marchantia polymorpha $\mathrm{L}$. using the insertion sites of trnA and trnI fragments from IR region (Bock and Maliga 1995; Chiyoda et al. 2007; K Mühlbauer et al. 2002; Lelivelt et al. 2005; López-Ochoa et al. 2015; Staub and Maliga 1992). In our lab, the same trnA/trnI of IR region was targeted to recover transplastomic lines of Momordica charantia by a Cucumis sativus based heterologous vector (CuIA) (Narra et al. 2018b) and obtained 2 transplastomic lines from 15 bombarded plates using petiole explants. Two different plastid vectors, KNTc, and pFaadAII targeting trnR/trnN and rpl32/trnL of IR and SSC regions of plastid genomes were employed to transform chloroplasts of S.dulcis (Muralikrishna et al. 2016; Narra et al. 2018a). Using these vectors, two transplastomic lines were recovered from 25 bombarded explants i.e 8\%, whereas, in the current investigation three transplastomic lines were recovered from 25 transformed explants i.e $12 \%$. In tobacco transplastomic lines synthetic bar gene was expressed by targeting trnV and $r p s 12$ which produced $7 \%$ of the total soluble protein (Lutz et al. 2001), whereas by targeting $\operatorname{trn} A$ and $t r n I$ of the tobacco plastids, $29.6 \%$ of fused anthrax protective antigen (PA) with cholera toxin B-subunit (CTB) protein was expressed in total soluble protein (Ruhlman et al. 2010). Increased transformation efficiency might be due to the choosing of the different intergenic insertion site. $\operatorname{trnA} / \mathrm{trn} \mathrm{i}$ is the most frequently used insertion site in plastid transformation experiments which directs the foreign gene sequences into inverted repeat region of plastome. trnI regions holds oriA within it that enables targeted foreign DNA replications in the chloroplasts and by the gene conversion the inserted foreign gene will be rapidly copied into another inverted repeat region (Lugo et al. 2004).

\section{Conclusion}

The increased transformation efficiency in $S$. dulcis by targeting new insertion sites will be a useful target to introduce the desired gene into plastome. The main objective is to improve the medicinal properties of $S$. dulcis by eliciting useful gene pool for human benefits by expressing therapeutic genes.

\section{Acknowledgment}

K.S is thankful to CAS-TWAS for providing financial assistance to carry out the final year of research work in IGDB, CAS, Beijing, and UGC for financial assistance to provide UGC-PDFSS fellowship. A.S is greatly acknowledged to UGC for providing BSR faculty fellowship. A.V is greatly thankful to DST-INSPIRE for financial assistance. We also thankful to UGC for financial support under SAP-DRS.

\section{Conflict of interest}

Authors don't have any conflict of interest.

\section{Reference}

Aileni M, Abbagani S, Zhang P (2011a) Highly efficient production of transgenic Scoparia dulcis L. mediated by Agrobacterium tumefaciens: plant regeneration via shoot organogenesis Plant Biotechnol Rep 5:147-156

Aileni M, Kokkirala VR, Yarra R, Vemunoori AK, Kasula K, Umate P, Abbagani S (2011b) In Vitro Regeneration, Flowering and Seed Formation from Leaf Explants of Scoparia dulcis L Global Science Books 5

Bock R, Maliga P (1995) In vivo testing of a tobacco plastid DNA segment for guide RNA function in psbL editing Molecular and General Genetics MGG 247:439-443

Boynton JE, Gillham NW, Harris EH, Hosler JP, Johnson AM, Jones AR, Randolph-Anderson BL, Robertson D, Klein TM, Shark KB (1988) Chloroplast transformation in Chlamydomonas with high velocity microprojectiles Science 240:1534-1538

Cheng L, Li H-P, Qu B, Huang T, Tu J-X, Fu T-D, Liao Y-C (2010) Chloroplast transformation of rapeseed (Brassica napus) by particle bombardment of cotyledons Plant cell reports 29:371-381

Chiu-Ming C, Ming-Tyan C (1976) 6-methoxybenzoxazolinone and triterpenoids from roots of $<\mathrm{i}>$ Scoparia dulcis $</ \mathrm{i}>$ Phytochemistry 15:1997-1999

Chiyoda S, Linley PJ, Yamato KT, Fukuzawa H, Yokota A, Kohchi $\mathrm{T}$ (2007) Simple and efficient plastid transformation system for the liverwort Marchantia polymorpha L. suspension-culture cells Transgenic research 16:41-49

De Farias Freire SM, Da Silva Emim JA, Lapa AJ, Souccar C, Torres LMB (1993) Analgesic and antiinflammatory properties of Scoparia dulcis L. extracts and glutinol in rodents Phytotherapy Research 7:408-414 
Doyle J (1991) DNA protocols for plants. In: Molecular techniques in taxonomy, vol 57. NATO ASI Series (Series H: Cell Biology). Springer, Berlin, Heidelberg, pp 283-293

Dufourmantel N, Pelissier B, Garcon F, Peltier G, Ferullo J-M, Tissot G (2004) Generation of fertile transplastomic soybean Plant molecular biology 55:479-489

Girish C, Vineela S, Reddy YN, Rajasekhar KK, Shankarananth V (2011) Antiulcer activity of aqueous extract of leaves of Scoparia dulcis (Linn.) in rats Journal of Pharmacy Research Vol. 4:p2526

Hayashi K, Hayashi T, Morita N (1992a) Cytotoxic and antitumour activity of scopadulcic acid B from Scoparia dulcis L Phytotherapy research : PTR 6:6-9

Hayashi K, Niwayama S, Hayashi T, Nago R, Ochiai H, Morita N (1988) In vitro and in vivo antiviral activity of scopadulcic acid B from Scoparia dulcis, Scrophulariaceae, against herpes simplex virus type 1 Antivir Res 9:345-354

Hayashi T (1999) Genetic Transformation of Scoparia dulcis L. In: Transgenic Medicinal Plants. Springer, pp 261-270

Hayashi T, Kawasaki M, Okamura K, Tamada Y, Morita N, Tezuka Y, Kikuchi T, Miwa Y, Taga T (1992b) Scoparic acid A, a $\beta-$ glucuronidase inhibitor from Scoparia dulcis $\mathrm{J}$ Nat Prod 55:1748-1755

Heifetz PB (2000) Genetic engineering of the chloroplast Biochimie 82:655-666

Hou B-K, Zhou Y-H, Wan L-H, Zhang Z-L, Shen G-F, Chen Z-H, Hu Z-M (2003) Chloroplast transformation in oilseed rape Transgenic research 12:111-114

K Mühlbauer S, Lössl A, Tzekova L, Zou Z (2002) Functional analysis of plastid DNA replication origins in tobacco by targeted inactivation The Plant Journal 32:175-184

Kanamoto H, Yamashita A, Asao H, Okumura S, Takase H, Hattori M, Yokota A, Tomizawa K-I (2006) Efficient and stable transformation of Lactuca sativa L. cv. Cisco (lettuce) plastids Transgenic research 15:205-217

Kota S, Lakkam R, Kasula K, Narra M, Qiang H, Allini VR, Zanmin $\mathrm{H}$, Abbagani S (2019) Construction of a species-specific vector for improved plastid transformation efficiency in Capsicum annuum L 3 Biotech 9:226

Kumar S, Dhingra A, Daniell H(2004a) Stable transformation of the cotton plastid genome and maternal inheritance of transgenes Plant Mol Biol 56:203-216 doi:10.1007/s11103-004-2907-y

Kumar S, Dhingra A, Daniell H(2004b) Stable transformation of the cotton plastid genome and maternal inheritance of transgenes Plant molecular biology 56:203-216

Lee SM, Kang K, Chung H, Yoo SH, Xu XM, Lee S-B, Cheong J-J, Daniell H, Kim M (2006) Plastid transformation in the monocotyledonous cereal crop, rice (Oryza sativa) and transmission of transgenes to their progeny Molecules and cells 21:401

Lelivelt CL, McCabe MS, Newell CA, Bastiaan deSnoo C, Van Dun KM, Birch-Machin I, Gray JC, Mills KH, Nugent JM (2005) Stable plastid transformation in lettuce (Lactuca sativa L.) Plant molecular biology 58:763-774

López-Ochoa L, Apolinar-Hernández M, Peña-Ramírez Y (2015)
Characterization of chloroplast region rrn16-rrn23S from the tropical timber tree Cedrela odorata L. and de novo construction of a transplastomic expression vector suitable for Meliaceae trees and other Genetics and Molecular Research 14:1469-1478

Lugo SK, Kunnimalaiyaan M, Singh NK, Nielsen BL (2004) Required sequence elements for chloroplast DNA replication activity in vitro and in electroporated chloroplasts J Plant science 166:151-161

Lutz KA, Knapp JE, Maliga P (2001) Expression of bar in the plastid genome confers herbicide resistance J Plant Physiology 125:1585-1590

Madanala R, Gupta V, Singh PK, Tuli R (2012) Development of chloroplast transformation vectors, and a new target region in the tobacco plastid genome Plant Biotechnol Rep 6:77-87 doi:DOI 10.1007/s11816-011-0204-1

Maliga P (2004) Plastid transformation in higher plants Annu Rev Plant Biol 55:289-313 doi:10.1146/annurev.arplant.55.031903. 141633

Miyahara T, Hayashi T, Matsuda S, Yamada R, Ikeda K, Tonoyama H, Komiyama H, Matsumoto M, Nemoto N, Sankawa U (1996) Inhibitory effects of scopadulcic acid B and its derivatives on bone resorption and osteoclast formation $<\mathrm{i}>\mathrm{in}$ vitro $</ \mathrm{i}>$ Bioorg Med Chem Lett 6:1037-1042

Muralikrishna N, Srinivas K, Kumar KB, Sadanandam A (2016) Stable plastid transformation in Scoparia dulcis L Physiology and Molecular Biology of Plants 22:575-581

Murashige T, Skoog F (1962) A revised medium for rapid growth and bio assays with tobacco tissue cultures Physiologia plantarum 15:473-497

Narra M, Kota S, Ellendula R, Kasula K, Kalva BK, Sadanandam A (2018a) Efficient chloroplast transformation in Scoparia dulcis L. using pFaadAII vector J Indian Journal of Plant Physiology 23:593-598

Narra M, Kota S, Velivela Y, Ellendula R, Allini VR, Abbagani S (2018b) Construction of chloroplast transformation vector and its functional evaluation in Momordica charantia L 3 Biotech 8:140 doi:10.1007/s13205-018-1160-z

Pari L, Latha M (2006) Antihyperlipidemic effect of Scoparia dulcis (sweet broomweed) in streptozotocin diabetic rats J Med Food 9:102-107

Ruf S, Hermann M, Berger IJ, Carrer H, Bock R (2001) Stable genetic transformation of tomato plastids and expression of a foreign protein in fruit Nature biotechnology 19:870-875

Ruhlman T, Verma D, Samson N, Daniell H (2010) The role of heterologous chloroplast sequence elements in transgene integration and expression J Plant physiology 152:2088-2104

Saikia R, Choudhury MD, Talukdar AD, Chetia P (2011) Antidiabetic Activity of Ethno Medicinal Plant Scoparia dulcis L. (Family: Scrophulariaceae): A Review Assam University Journal of Science and Technology 7:173-180

Sidorov V, Staub JM, Wan Y, Ye G(2019) Plastid Transformation of Maize. Google Patents

Sidorov VA, Kasten D, Pang SZ, Hajdukiewicz PT, Staub JM, Nehra NS (1999a) Stable chloroplast transformation in potato: use of green fluorescent protein as a plastid marker The Plant Journal 
19:209-216

Sidorov VA, Kasten D, Pang SZ, Hajdukiewicz PTJ, Staub JM, Nehra NS (1999b) Stable chloroplast transformation in potato: use of green fluorescent protein as a plastid marker Plant $\mathbf{J}$ 19:209-216

Sikdar S, Serino G, Chaudhuri S, Maliga P (1998) Plastid transformation in Arabidopsis thaliana Plant Cell Reports 18:20-24

Singh A, Verma S, Bansal K (2010) Plastid transformation in eggplant (Solanum melongena L.) Transgenic Research 19: 113-119

Srinivas K, Muralikrishna N, Kumar KB, Raghu E, Mahender A, Kiranmayee K, Yashodahara V, Sadanandam A (2016) Biolistic transformation of Scoparia dulcis L Physiology and Molecular Biology of Plants 22:61-68

Staub JM, Maliga P (1992) Long regions of homologous DNA are incorporated into the tobacco plastid genome by transformation The Plant Cell 4:39-45

Svab Z, Hajdukiewicz P, Maliga P (1990) Stable transformation of plastids in higher plants Proceedings of the National Academy of Sciences 87:8526-8530

Svab Z, Maliga P (1993) High-frequency plastid transformation in tobacco by selection for a chimeric aadA gene Proc Natl Acad Sci U S A 90:913-917

Verma D, Samson NP, Koya V, Daniell H (2008) A protocol for expression of foreign genes in chloroplasts Nature Protocols 3:739

Wang H-H, Yin W-B, Hu Z-M (2009) Advances in chloroplast engineering Journal of Genetics and Genomics 36:387-398

Wang Y, Wei Z, Xing S (2018) Stable plastid transformation of rice, a monocot cereal crop Biochemical and Biophysical Research Communications 503:2376-2379

Yamazaki M, Son L, Hayashi T, Morita N, Asamizu T, Mourakoshi I, Saito K (1996) Transgenic fertile Scoparia dulcis L., a folk medicinal plant, conferred with a herbicide-resistant trait using an Ri binary vector Plant Cell Rep 15:317-321 